\title{
Preface: Flood resilient communities - managing the consequences of flooding
}

\author{
A. H. Thieken ${ }^{1}$, S. Mariani ${ }^{2}$, S. Longfield ${ }^{3}$, and W. Vanneuville ${ }^{4, *}$ \\ ${ }^{1}$ University of Potsdam, Institute of Earth and Environmental Sciences, Karl-Liebknecht-Strasse 24-25, \\ 14476 Potsdam, Germany \\ ${ }^{2}$ Institute for Environmental Protection and Research (ISPRA), Via Vitaliano Brancati 48, 00144 Rome, Italy \\ ${ }^{3}$ Environment Agency, Lateral, 8 City Walk, Leeds, LS11 9AT, UK \\ ${ }^{4}$ European Environment Agency (EEA), Kongens Nytorv 6, 1050 Copenhagen K, Denmark \\ *on secondment from Flemish Government-Department of Mobility and Public Works, Belgium
}

Correspondence to: A. H. Thieken (thieken@uni-potsdam.de)

In recent years, Europe has suffered a number of severe coastal and river floods that harmed human health, and caused damage to properties, infrastructure, economic activities, cultural heritage and the environment. Some events were accompanied by severe surface water flooding which has evolved into a new hazard type to be considered in flood risk management. National governments have recognised the key role research can play in responding to these events and improving a society's resilience to floods in the future. Therefore, the CRUE (Coordination of the Research financed in the European Union on flood management) consortium was established in 2004 and funded as a European Research Area Network (ERA-Net) under the 6th EU Framework Programme for Research and Technological Development (FP6). Its aim was to consolidate existing European flood research programmes and projects, to promote best practices as well as to identify gaps and opportunities for collaboration. The vision of the CRUE consortium is to provide a coordinated and comprehensive transnational evidence base on flood risk management, which could be used to underpin the work of national and European policy-makers.

At the same time, EU Member States recognised the need to provide a legal European framework to assess and manage flood risks. In parallel with the EU Water Framework Directive 2000/60/EC (EC, 2000) - the cornerstone of EU water protection policy - the European Parliament and the Council of the European Union adopted the Floods Directive 2007/60/EC in October 2007 (EC, 2007). The EU Floods Directive requires that the member states perform a preliminary flood risk assessment by December 2011, prepare flood hazard and risk maps for areas with (potentially) significant flood risk by December 2013 and establish flood risk management plans by December 2015 (EC, 2007). In response to this tight schedule, the CRUE Consortium decided to support the implementation of the EU Floods Directive and identified five strategic research areas (Pichler and Jackson, 2009):

1. Developing resilience and adapting to increasing flood risks: climate change and new developments;

2. Risk assessment and mapping;

3. Implementing transnational based strategies on flood event management and recovery;

4. Meeting the multifunctional demands on flood prevention and protection and their sustainable management; and

5. Addressing public knowledge of flood risk and enhancing awareness, perception and communications.

This agenda has been implemented by the CRUE Consortium in different ways; funding two joint calls for research were among the most important. The first CRUE funding initiative centred on risk assessment and risk management. In particular, it focused on the effectiveness and efficiency of non-structural flood risk management measures. Key research results and conclusions of the seven funded projects were summarized by Pichler et al. (2009).

The second funding initiative focused on flood resilient communities and managing the consequences of flooding. Seven joint research projects and a scientific coordination project were funded. Key findings and recommendations 
for policymakers, practitioners and researchers were summarised by Beurton and Thieken (2012) and were formally presented to the Working Group on Floods (WG F) of the European Commission's Common Implementation Strategy (CIS) for the Water Framework Directive in April 2012. The CRUE Consortium was represented in WG F and, as such, recognised as a route for information exchange on national and European-wide flood-related research with a clear link to the implementation of the EU Floods Directive.

For the scientific community, this Special Issue in Natural Hazards and Earth System Sciences was launched, in which research approaches and innovative results from single CRUE projects as well as cross-project findings are presented. In total, this Special Issue contains eight papers, which cover different aspects of risk management and resilience; these terms will be defined in the next section after which the papers will be introduced.

\section{Risk management and resilience}

To reduce the risk of natural hazards becoming disasters, the implementation of adequate prevention, protection and/or preparedness measures is necessary. The cycle of integrated risk management is a generally accepted concept that has been widely used by national and international organisations. Various versions have been published; examples can be found in DKKV (2003), FOCP (2003) or EEA (2011). The cycle describes the consecutive phases that a society should undertake to improve its resilience against natural hazards. The process often starts after severe events as described by Kienholz et al. (2004) or Thieken et al. (2007) with (1) an emergency response during or immediately after a hazardous event to limit adverse effects; (2) recovery and reconstruction to regain a standard of living comparable to the pre-event status; (3) event and risk analysis including a systematic analysis of possible hazard and risk scenarios in the region under study and a transparent risk assessment; and (4) planning and implementation of preventive, precautionary and preparatory measures that reduce the level of risk.

Initiatives with a dedicated focus on prevention like the EU Floods Directive require that the process starts with (1) a systematic risk identification and analysis, which is followed by (2) an assessment and prioritisation of risks as well as (3) decisions on efficient and effective prevention measures and (4) their implementation. A final step includes (5) monitoring and reporting which may result in a re-assessment of risks that might require altered or new prevention measures. Risk management in this sense is an iterative optimisation process that is not (necessarily) event-driven and has to be seen as a spiral, in which risk analysis, assessment and prevention are repeated processes (Kienholz et al., 2004; Meyer et al., 2013). The EU Floods Directive accounts for this iteration by demanding a review of the preliminary flood risk assessment by December 2018, of the flood hazard and risk maps by December 2019 and of the flood risk management plans by December 2021 and every six years thereafter (EC, 2007).

Recent extreme events have, however, challenged conventional thinking due to event magnitudes never experienced before, new locations of occurrence, or unforeseen cascading effects. Against this background, one has to accept that absolute safety and complete prevention are impossible. Therefore, approaches for coping with unpredictable hazards and changes are needed (e.g., Berkes, 2007). In this context, resilience has been introduced as a concept that highlights the ability to learn how to cope with unanticipated hazards (e.g., Wildavsky, 1988 in Lorenz, 2013). In addition to risk management, resilience analysis can improve "the system response to surprises" (Park et al., 2013, p. 365).

However, the concept of resilience is still diverse, since the term has been used in very different fields of research. Starting in psychology and psychiatry in the 1940s (Manyena, 2006) and system ecology in the 1970s (Holling, 1973), it propagated to social sciences and risk and natural hazards research, where the connection of resilience and adaptation to natural hazards was made (Schwindt and Thieken, 2010).

A closer look at the multiple definitions, provided for example by Thywissen (2006) and Mayunga (2007), reveals that the concept of resilience to natural hazards mainly builds on three pillars: resistance, recovery and adaptive capacity (Maguire and Hagan, 2007; Schwindt and Thieken, 2010).

Resistance is the ability of a system to resist a disturbance caused by a natural event and is measured by the amount of disturbance the system can withstand or absorb before any changes occur. According to Dovers and Handmer (1992), this is a reactive approach to resilience that aims to strengthen the status quo in order to be able to withstand changes while remaining functional. This concept of resilience hence focuses on persistence and robustness (Folke, 2006).

The recovery aspect of resilience is measured by the time a system needs to return to its original state (Pimm, 1984; Klein et al., 2003; Füssel and Klein, 2006). The quicker the pre-disaster growth path is (re-)achieved, the more resilient a community or system is considered to be. However, this approach has been criticized since a fixed reference state is often lacking in coupled social and ecological systems (Berkes, 2007). Therefore, the relationship in time may be better framed in terms of returning to an acceptable level of functioning and structure (IRIN, 2005). In addition, many systems are dynamic and able to adjust to external changes. In this respect, a return to the original equilibrium is not an improvement, since the system has not advanced in its capacity to cope with a shock (see, e.g., Klein et al., 2003).

This leads us to the third aspect of resilience that has emerged in recent years and was at the focus of the CRUEfunded research projects and papers of this Special Issue. Creativity or adaptive capacity is the ability of a system to learn from past events and to adapt in such a way that it 
develops beyond the pre-event status. According to Dovers and Handmer (1992), this proactive understanding of resilience accepts upcoming changes in the system and aims to develop a regime that is able to adjust to new conditions. It also includes the willingness and the ability of a society to learn and adjust to changes (Watts and Bohle, 1993; Klein et al., 2003). In this understanding, processes and capacities, not the status, characterize a system's ability to cope with (changing) risks (Pelling, 2003; Young et al., 2006). Park et al. (2013) understand resilience as the outcome of a repeated process of sensing, anticipation, learning, and adaptation. In this sense, learning from past events (and during events) at the level of single individuals, but also at the level of institutions and organisations is an important characteristic of resilience. (Institutional) Learning processes may have several facets like self-organization, transformability, adaptation as response to perturbations, adaptive management, use of all kinds of knowledge and innovation (Folke et al., 2005; Folke, 2006; Berkes, 2007; Gardner and Dekens, 2007; IPCC, 2007). With many aspects involved, the term resilience runs the risk of being used in many different contexts without a proper definition or meaning and hence becoming a new buzz word. After 1973, the use of the term resilience has already increased exponentially in print (Park et al., 2013).

\section{Enhancing flood resilience of communities}

Resilience enhancement has already become a guiding principle in various national, European and international strategies on civil and environmental protection, for instance the priority action 3 of the Hyogo Framework for Action (UNISDR, 2005, 2011), including policies for sustainable development (UN-CSD, 2012) and climate change adaptation, such as the EU Strategy on Adaptation to Climate Change (EC, 2013). Furthermore, the EU Floods Directive was adopted in order to foster learning and resilience also in regions that have not experienced flooding recently. Within the second CRUE funding initiative, various approaches, methods and guidelines were developed, tested and validated in a total number of 35 European case studies (see Fig. 1) to enhance flood-related resilience and to support the implementation of the EU Floods Directive. Due to the differing emphases and goals of the projects the case study areas represent manifold and heterogeneous characteristics of the natural and social environment (see Thieken et al., 2011). An analysis by Beurton and Thieken (2012) revealed that there was a focus on regions that are at risk of fluvial flooding or combined sources of flooding covering a wide range of catchment area sizes. Furthermore, there was a tendency to investigate case studies that had recently been affected by flooding (within the last ten years).

The papers of this Special Issue contribute to resilience enhancement at different phases of the risk management cycle. In order to improve emergency management, Lumbroso et

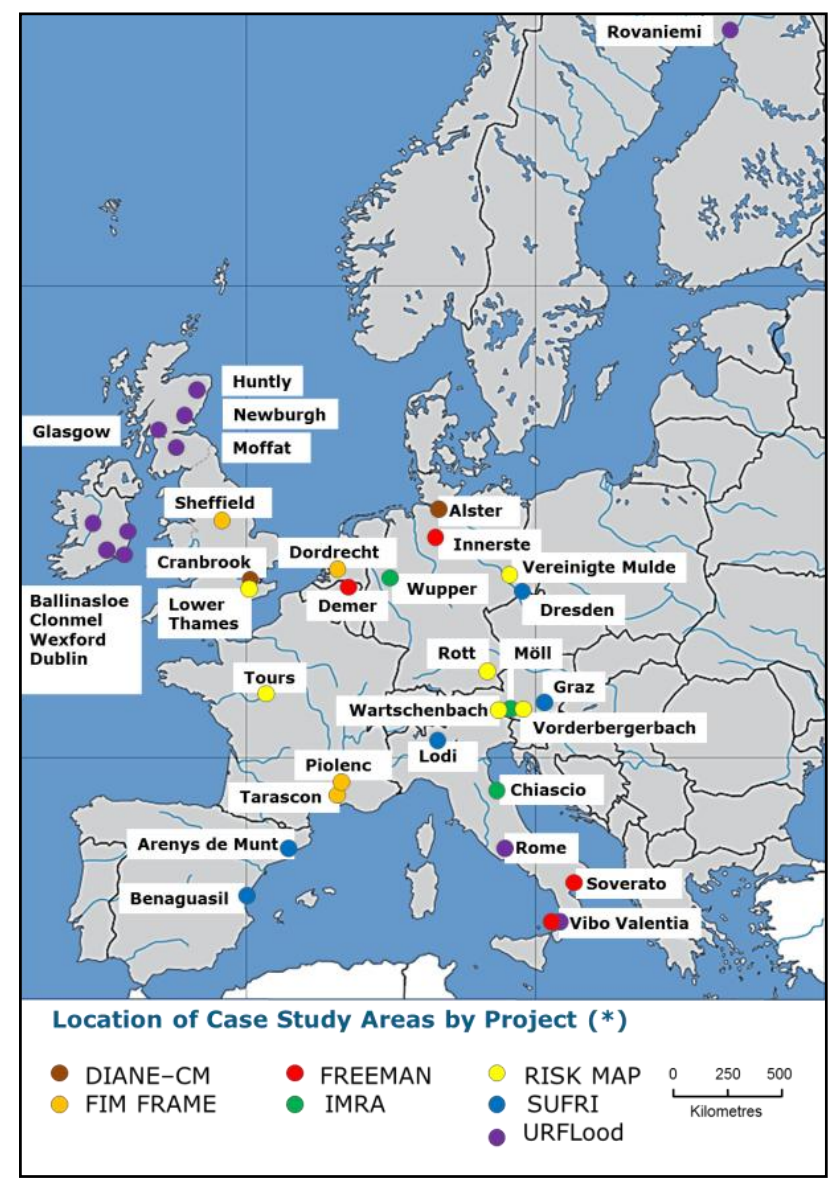

Fig. 1. Location map of the case study areas by project, where DIANE-CM stand for "Decentralised Integrated Analysis and Enhancement of Awareness through Collaborative Modelling and Management of Flood Risk", FIM FRAME for "Flood Incident Management - A FRAMEwork for improvement", FREEMAN for "Flood REsilience Enhancement and MANagement", IMRA for "Integrative flood risk governance approach for improvement of risk awareness and increased public participation", RISK MAP for "Improving Flood Risk Maps as a Means to Foster Public Participation and Raising Flood Risk Awareness: Towards Flood Resilient Communities", SUFRI for "Sustainable Strategies of Urban Flood Risk Management with non-structural measures to cope with the residual risk", URFlood for "Understanding Uncertainty and Risk in communicating about FLOODs" (Source: Beurton and Thieken, 2012, political map of Europe from Liuzzo, 2006).

al. (2012) describe a systematic method for assessing and improving flood emergency plans. Based on an analysis of existing emergency plans and stakeholder workshops in France, the Netherlands and England, a framework was developed that allows relevant stakeholders to apply the three-stage process - appraise, tackle and implement - to a range of flood emergency plans. Pilot applications showed that the framework provided a logical method for analysing flood emergency plans. It helped to identify gaps in and assumptions 
made by such plans and allowed the collection and collation of detailed information required for their set-up and update (Lumbroso et al., 2012). On the basis of the feedback provided by stakeholders, the process was streamlined to enable easier application. Its application was perceived to be more effective when a "strong" member of the emergency management team acted as facilitator, who encouraged the discussion and pushed the process (Lumbroso et al., 2012).

For tasks in the risk analysis and assessment phase, Escuder-Bueno et al. (2012) present two methodologies which aim to support informed decisions on the implementation of non-structural protection measures. First, a comprehensive and quantitative tool for flood risk analysis for pluvial and river flooding in urban areas is introduced. Secondly, a methodology for the investigation of risk awareness of the population at risk is presented as a basis to estimate current risks from a social perspective and to identify the way floods are understood by citizens. Thereby, quantitative estimates of flood risk, before and after investing in non-structural risk mitigation measures, are provided, which decision makers can use. In the five case studies considered by Escuder-Bueno et al. (2012) huge differences in citizens' opinions were found. From this result it was concluded that risk reduction strategies have to be tailored to the needs and contexts of each case study/urban area.

Evers et al. (2012) followed an interactive, collaborative modelling approach for risk analyses and assessment. Through interaction it was intended to stimulate a social learning process that enhances the social capacity of the stakeholders involved. It was further aimed to better understand, how data and maps from hazard and vulnerability analyses and near-real-time flood forecasts could be used to open a dialogue with the public, to enable more informed and shared decision-making and to enhance flood risk awareness. The project succeeded in jointly developing and ranking alternatives for flood risk management in the two case studies investigated by the collaborative approach. Thereby, a basis for further planning and management was created (Evers et al., 2012).

Public participation leading to governance-related decision-making as required by the EU Floods Directive is also addressed by Fleischhauer et al. (2012). In their opinion, this requirement has two perspectives. On the one hand, the question of how decision-makers can improve the quality of their governance process arises. For this, a risk governance assessment tool was developed, which consists of an indicator-based benchmarking and monitoring tool, by which the performance of a flood risk management system with regard to ideal risk governance principles can be evaluated (Fleischhauer et al., 2012). On the other hand, the question of how the public should be appropriately informed and involved evolves. Here, Fleischhauer et al. (2012) used the social milieu approach to develop adequate risk communication and awareness strategies. The social milieus provide information on lifestyles, attitudes and values of the people in the regions under study. This knowledge was further used to design appropriate information and participation activities for the general public (Fleischhauer et al., 2012).

A couple of other papers concentrated on risk perception and improved flood risk communication. Bradford et al. (2012) used a novel approach in exploring the role of public perception in developing flood risk communication strategies and flood risk management plans in Europe. The approach is based on 1375 questionnaire responses that were collected by two CRUE-funded research projects in thirteen communities from six European countries.

Bradford et al. (2012) and O'Sullivan et al. (2012) conceptualised risk perception as a pillar of social resilience which is represented by risk awareness, worry and preparedness. It was assumed that awareness contributes to worry and worry contributes to preparedness with the effect that elevating any of the three indicators raises perception and resilience. However, worry was not found to be the central link between awareness and preparedness. Therefore, Bradford et al. (2012) recommend that communication strategies should not aim to evoke fear in communities at risk. The study further revealed that experience of floods significantly raised all three elements of perception. Therefore, knowledge from flood victims could be used as a resource in flood risk communication. For example, personal accounts from flood victims could highlight adverse impacts of flooding and, by this emphasise the need to undertake precautionary measures. In addition, by providing specific information on easily implementable measures, their implementation is facilitated, since this increases perceived personal ability to protect property (Bradford et al., 2012).

Using a similar data set, O'Sullivan et al. (2012) investigated how to improve risk communication in practice. It was found that a common assumption of flood communications, which suggests that there is an information deficit that can be overcome by the provision of more and better information, is insufficient. The communication process is multidimensional and current practice can be improved based on the recommendations that were derived from the survey responses. Improved awareness of current flood information sources, the clarification of responsibilities of authorities, the development of flood risk statements that are understandable for the general public as well as the provision of information on how to prepare for a flood are seen as core improvements by O'Sullivan et al. (2012).

Risk communication by flood hazard and risk maps was in the focus of work presented by Meyer et al. (2012). As aforementioned, the EU Floods Directive requires the creation of flood hazard and risk maps by December 2013 (EC, 2007). According to Meyer et al. (2012), current mapping practices are frequently only seen as an information tool rather than a communication tool. Hence, local knowledge is not incorporated. Moreover, map contents often do not match the requirements of the end-users. These gaps were tackled by Meyer et al. (2012) by end-user participation in 
the mapping process, for instance, by interviews, workshops and eye-tracking tests in five European case studies. The outcomes of this research are summarized and presented in "idealised" maps for different user groups, namely, strategic planning, emergency management and the general public (Meyer et al., 2012).

The implementation of the EU Floods Directive can be seen as an opportunity for Member States to revise their own flood risk governance. Mysiak et al. (2013) investigated this by examining the historical development of flood risk governance in Italy, a country prone to natural hazards of many kinds. It is illustrated in the paper that, over the last six decades, governance has evolved as a consequence of many severe flood events. Mysiak et al. (2013) further outline how the recommendations provided from three complementary CRUE-funded research projects could support its revision.

\section{Participation}

The papers in this Special Issue demonstrate that participation and collaboration were at the core of CRUE-funded research projects. With regard to public authorities, the vast majority of stakeholders was represented by (flood or environmental) authorities and agencies ranging from municipal and provincial to federal levels. These were followed by civil protection units and fire brigades (Thieken et al., 2011). Most stakeholders were involved by participating in workshops and meetings (e.g. Evers et al., 2012) or by contributing information during (semi-)structured interviews and experiments (e.g. Meyer et al., 2012). To a far lesser extent stakeholders played the role of a full or associated project partner, the work presented by Fleischhauer et al. (2012) being an exception. This kind of intense collaboration was, however, seen to be highly important for the operational implementation of the research in the case study area as well as for the continuation of communication and other activities beyond the funding period (Beurton and Thieken, 2012). Besides, other ways for intensive exchange of experiences and knowledge-transfer from science into practice were realised in the CRUE-funded projects. Researchers who worked at public authorities for a while or a "Tandem" solution, which means that a scientific partner and a stakeholder worked together in a particular case study as implemented by Evers et al. (2012), were judged as successful concepts. On the other hand, hindrances for the interaction with stakeholders were limited resources for identifying and understanding local specifics as well as a lacking data (Beurton and Thieken, 2012).

With regard to strengthening public participation in enhancing resilience and in establishing future flood risk management plans, the main outcome in several case studies was that the general public needs and wants more information. Therefore, a careful analysis of public views needs to become more common when designing risk communication strategies. Good participation can be achieved through public opinion polls (Bradford et al., 2012; Escuder-Bueno et al., 2012; O’Sullivan et al., 2012). Nevertheless, by using public opinion polls, it is difficult to ensure equal representation of all sectors of the community. The main insight from the CRUE-funded research projects was that a single solution to reach a maximum of recipients at once does not exist, but must be adapted to the target audience, as for example, demonstrated by Fleischhauer et al. (2012) by the social milieu approach, as well as to the context in which communication and participation takes place, for instance mapping (Meyer et al., 2012), scenario development (Evers et al., 2012) or flood warning (Bradford et al., 2012).

\section{Conclusions and perspectives}

Altogether, the CRUE-funded research projects improved public dialogue on flood risks and increased the awareness, acceptance and understanding of - among others - maps, scenarios and models in the case study areas (Beurton and Thieken, 2012).

The systematic approaches of the CRUE researches presented in this Special Issue revealed that there are on the one hand weaknesses in flood risk management and resilience enhancement that are, for example, due to missing expertise and skills for risk communication in the administrations that are in charge. On the other hand, specific demands of stakeholders, such as flood maps for emergency response being different from maps for strategic planning (Meyer et al., 2012), could also be carved out.

However, countries and regions greatly differ in terms of their geographical, institutional and participatory landscape. Therefore, the transfer and application of the methods presented in this Special Issue can be limited by several factors. When either financial, personnel or data resources are missing, the implementation of flood risk management approaches is restricted. Also cultural aspects, like the local history and flood risk experiences, in addition to values, beliefs and social milieus may influence the applicability of a certain approach. At least political aspects, like personal motivation, complacency of institutions or the size of a community, need to be considered before strategies are taken into action (Beurton and Thieken, 2012). Moreover, flood research and risk management have to deal with natural and social uncertainties, such as climate change and multiple knowledge frames, or conflicting ways of understanding a system. Additional restrictions for the generalization of the results and the transferability of methods are due to characteristics of different flood types (pluvial, fluvial, coastal), for instance with regard to differences in lead times of flood warnings, predictability and potential impacts (Beurton and Thieken, 2012). Therefore, the suitability of each approach needs to be verified for each region under study and its specific requirements. Advocating a one-size-fits-all approach is not a recommended solution. 
In countries where investigations were performed, CRUE research has already led to changes in communication strategies, like a changed wording of flood statements (e.g. in Finland, Minna Hanski from the ministry of Agriculture and forestry in Finland during the WG Floods meeting, personal communication, in April 2012). Methods applied and recommendations derived from the case studies are seen to be applicable to other risks and transferable to jurisdictions beyond the case study areas and project countries (O'Sullivan et al., 2012). Currently, it is too early to comprehensively assess the transferability and practical relevance of the CRUEfunded research. Its uptake in flood risk management plans to be published by December 2015 in the frame of the EU Floods Directive will be an indicator that should be monitored in the near future.

Acknowledgements. This Special Issue in Natural Hazards and Earth System Sciences was part of the Scientific Coordination Project funded within the Era-Net CRUE Second Funding Initiative "Flood Resilient Communities - Managing the Consequences of Flooding". Funding by all CRUE partners as well as collaboration with and support from all CRUE-funded projects are gratefully acknowledged.

As guest editors, we would also like to thank the journal managing editor, Fausto Guzzetti, for giving us the opportunity to publish this Special Issue.

\section{References}

Berkes, F.: Understanding uncertainty and reducing vulnerability: lessons from resilience thinking, Nat. Hazards, 41, 283-295, 2007.

Beurton, S. and Thieken, A.H.: Addressing the key findings of research related to "Flood resilient communities - managing the consequences of flooding", Synthesis Report of the Second ERA-Net CRUE Funding Initiative, 22 pp., available at: http: //www.crue-eranet.net/partner_area/documents/CRUE_2nd_ Research_Funding_Initiative_-_Synthesis_Report_2012.pdf (last access: 19 October 2013), 2012.

Bradford, R. A., O’Sullivan, J. J., van der Craats, I. M., Krywkow, J., Rotko, P., Aaltonen, J., Bonaiuto, M., De Dominicis, S., Waylen, K., and Schelfaut, K.: Risk perception - issues for flood management in Europe, Nat. Hazards Earth Syst. Sci., 12, 2299-2309, doi:10.5194/nhess-12-2299-2012, 2012.

DKKV - Deutsches Komitee Katastrophenvorsorge (German Committee Disaster Risk Reduction) (Ed.): Hochwasservorsorge in Deutschland - Lernen aus der Katastrophe 2002 im Elbegebiet, DKKV-Report 29, Bonn, Germany, 2003.

Dovers, S. R. and Handmer, J. W.: Uncertainty, sustainability and change, Global Environ. Chang., 2, 262-276, 1992.

EC - European Commission: Directive 2000/60/EC of the European Parliament and of the Council of 23 October 2000 establishing a framework for Community action in the field of water policy (Water Framework Directive), 2000.

EC - European Commission: Directive 2007/60/EC of the European Parliament and of the Council of 23 October 2007 on the assessment and management of flood risks (Floods Directive), 2007.

EC - European Commission: Communication from the Commission to the European Parliament, the Council, the European Economic and Social Committee and the Committee of the Regions on An EU Strategy on adaptation to climate change, COM(2013)216 final, 2013.

EEA - European Environment Agency: Mapping the impacts of natural hazards and technological accidents in Europe, EEA Technical report No 13/2010, 2011.

Escuder-Bueno, I., Castillo-Rodríguez, J. T., Zechner, S., Jöbstl, C., Perales-Momparler, S., and Petaccia, G.: A quantitative flood risk analysis methodology for urban areas with integration of social research data, Nat. Hazards Earth Syst. Sci., 12, 2843-2863, doi:10.5194/nhess-12-2843-2012, 2012.

Evers, M., Jonoski, A., Maksimovič, Č., Lange, L., Ochoa Rodriguez, S., Teklesadik, A., Cortes Arevalo, J., Almoradie, A., Eduardo Simões, N., Wang, L., and Makropoulos, C.: Collaborative modelling for active involvement of stakeholders in urban flood risk management, Nat. Hazards Earth Syst. Sci., 12, 28212842, doi:10.5194/nhess-12-2821-2012, 2012.

Fleischhauer, M., Greiving, S., Flex, F., Scheibel, M., Stickler, T., Sereinig, N., Koboltschnig, G., Malvati, P., Vitale, V., Grifoni, P., and Firus, K.: Improving the active involvement of stakeholders and the public in flood risk management - tools of an involvement strategy and case study results from Austria, Germany and Italy, Nat. Hazards Earth Syst. Sci., 12, 2785-2798, doi:10.5194/nhess-12-2785-2012, 2012.

FOCP - Swiss Federal Office for Civil Protection: Integral Risk Management Cycle, 2003, available at: http://www.bevoelkerungsschutz.admin.ch/internet/bs/en/home/ themen/gefaehrdungen-risiken.html, last access: 19 October 2013.

Folke, C.: Resilience: The emergence of a perspective for socialecological system analyses, Global Environm. Chang., 16, 253267, 2006.

Folke, C., Hahn, T., Olsson, P., and Norberg, J.: Adaptive governance of social-ecological systems, Ann. Rev. Environ. Resources, 30, 441-473, 2005.

Füssel, H.-M. and Klein, R.: Climate Change Vulnerability Assessments: An Evolution of Conceptual Thinking, Climatic Change, 75, 301-329, 2006.

Gardner, J. A. and Dekens, J.: Mountain hazards and the resilience of social-ecological systems: lessons learned in India and Canada, Nat. Hazards, 41, 317-336, 2007.

Holling, C. S.: Resilience and stability of ecological systems, Ann. Rev. Ecol. System., 4, 2-23, 1973.

IPCC - International Panel on Climate Change: Climate Change 2007: Impacts, Adaptation and Vulnerability, Contribution of the Working Group II to the Fourth Assessment Report of the Intergovernmental Panel on Climate Change, Cambridge University Press, Cambridge and New York, 2007.

IRIN - Integrated Regional Information Network: Natural disasters - a heavy price to pay, Disaster reduction and the human cost of disaster, IRIN Web Special, 3-6, available at: http://www.irinnews.org/indepthmain.aspx? IndepthId= 14\&ReportId=62446 (last access: 19 October 2013), 2005.

Kienholz, H., Krummenacher, B., Kipfer, A., and Perret, S.: Aspects of Integral Risk Management in Practice - Considerations 
with Respect to Mountain Hazards in Switzerland, Österreichische Wasser- und Abfallwirtschaft, 56, 43-50, 2004.

Klein, R. J. T., Nicholls, R. J., and Thomalla, F. T.: Resilience to natural hazards: how useful is the concept?, Environ. Hazards, 5, 35-45, 2003.

Liuzzo, D.: Europe_location.png, available at: http://commons. wikimedia.org/wiki/File:Europe_location.png\#filelinks (last access: 19 October 2013), 2006.

Lorenz, D. F.: The diversity of resilience: contributions from a social science perspective, Nat. Hazards, 67, 7-24, 2013.

Lumbroso, D. M., Di Mauro, M., Tagg, A. F., Vinet, F., and Stone, K.: FIM FRAME: a method for assessing and improving emergency plans for floods, Nat. Hazards Earth Syst. Sci., 12, 17311746, doi:10.5194/nhess-12-1731-2012, 2012.

Maguire, B. and Hagan, P.: Disasters and communities: understanding social resilience, Australian J. Emergency Manage., 22, 1620, 2007.

Manyena, S. B.: The concept of resilience revisited, Disasters, 30(4), 433-450, 2006.

Mayunga, J. S.: Understanding and Applying the Concept of Community Disaster Resilience: A capital-based approach, Working Paper prepared for the summer academy for social vulnerability and resilience building, Munich, Germany, 2007.

Meyer, V., Kuhlicke, C., Luther, J., Fuchs, S., Priest, S., Dorner, W., Serrhini, K., Pardoe, J., McCarthy, S., Seidel, J., Palka, G., Unnerstall, H., Viavattene, C., and Scheuer, S.: Recommendations for the user-specific enhancement of flood maps, Nat. Hazards Earth Syst. Sci., 12, 1701-1716, doi:10.5194/nhess-121701-2012, 2012.

Meyer, V., Becker, N., Markantonis, V., Schwarze, R., van den Bergh, J. C. J. M., Bouwer, L. M., Bubeck, P., Ciavola, P., Genovese, E., Green, C., Hallegatte, S., Kreibich, H., Lequeux, Q., Logar, I., Papyrakis, E., Pfurtscheller, C., Poussin, J., Przyluski, V., Thieken, A. H., and Viavattene, C.: Review article: Assessing the costs of natural hazards - state of the art and knowledge gaps, Nat. Hazards Earth Syst. Sci., 13, 1351-1373, doi:10.5194/nhess-13-1351-2013, 2013.

Mysiak, J., Testella, F., Bonaiuto, M., Carrus, G., De Dominicis, S., Ganucci Cancellieri, U., Firus, K., and Grifoni, P.: Flood risk management in Italy: challenges and opportunities for the implementation of the EU Floods Directive (2007/60/EC), Nat. Hazards Earth Syst. Sci., 13, 2883-2890, doi:10.5194/nhess-132883-2013, 2013.

O’Sullivan, J. J., Bradford, R. A., Bonaiuto, M., De Dominicis, S., Rotko, P., Aaltonen, J., Waylen, K., and Langan, S. J.: Enhancing flood resilience through improved risk communications, Nat. Hazards Earth Syst. Sci., 12, 2271-2282, doi:10.5194/nhess-122271-2012, 2012.

Park, J., Seager, T. P., Rao, P. S. C., Convertino, M., and Linkov, I.: Integrating Risk and Resilience Approaches to Catastrophe Management in Engineering Systems, Risk Anal., 33, 356-367, doi:10.1111/j.1539-6924.2012.01885.x, 2013.

Pelling, M.: The Vulnerability of cities: Natural disasters and social resilience, Earthscan, London, UK, 2003.
Pichler, A. and Jackson, V.: CRUE Research Agenda - Strengthening European Research for Flood Risk Management, CRUE Consortium Report, 37 pp., available at: http://www.crue-eranet.net/ partner_area/documents/Final_version_CRUE_RA_v4_5.pdf (last access: 19 October 2013), 2009.

Pichler, A., Deppe, T., and Jackson, V.: Key findings of research related to Risk Assessment and Risk management: effectiveness and Efficiency of Non-Structural Flood Risk management measures, CRUE Synthesis Report, 21 pp., available at: http://www.crue-eranet.net/partner_area/documents/CRUE_ 1st_Research_Funding_Initiative_Synthesis_report.pdf (last access: 19 October 2013), 2009.

Pimm, S. L.: The complexity and stability of ecosystems, Nature, 307, 321-326, 1984.

Schwindt, M. and Thieken, A. H.: Review on Resilience, 3rd CRUE Snapshot, 8-15, available at: http://www.crue-eranet.net/ partner_area/documents/CRUE_snapshot_2010_final.pdf (last access: 19 October 2013), 2010.

Thieken, A. H., Kreibich, H., Müller, M., and Merz, B.: Coping with floods: preparedness, response and recovery of flood-affected residents in Germany in 2002, Hydrol. Sci. J., 52, 1016-1037, 2007.

Thieken, A. H., Moran, A., and Schwindt, M.: Research on flood resilient communities - Overview and preliminary analysis of case studies within the second ERA-NET CRUE funding initiative, in: Urban Flood Risk Management - Approaches to enhance resilience of communities, edited by: Zenz, G. and Hornich, R., Proceedings of the International Symposium UFRIM, Graz, 2123 September 2011, 485-490, 2011.

Thywissen, K.: Components of Risk - A Comparative Glossary, United Nation University, Publication Series of UNU-EHS, No. 2/2006, 2006.

UN-CSD - United Nations Conference of Sustainable Development: The Future We Want, Outcome Document of the UN-CSD in Rio de Janeiro, Brazil, 20-22 June 2012, A/RES/66/288, 53 pp., 2012.

UN-ISDR - International Strategy for Disaster Reduction: Hyogo Framework for Action 2005-2015: Building the Resilience of Nations and Communities to Disasters, World Conference on Disaster Reduction, 18-22 January 2005, Kobe, Hyogo, Japan, 2005.

UN-ISDR - International Strategy for Disaster Reduction: Hyogo Framework for Action 2005-2015: Building the Resilience of Nations and Communities to Disasters, Mid-term Review 20102011, Report, 107 pp., available at: http://www.unisdr.org/files/ 18197_midterm.pdf (last access: 19 October 2013), 2011.

Watts, M. J. and Bohle, H. G.: The space of vulnerability: the causal structure of hunger and famine, Prog. Human Geog., 17, 43-67, 1993.

Wildavsky, A. B.: Searching for Safety, Transaction, New Brunswick, NJ, 1988.

Young, O., Berkhout, F., Gallopin, G., Janssen, M., Ostrom, E., and Vanderleeuw, S.: The globalization of socio-ecological systems: An agenda for scientific research, Global Environ. Chang., 16, 304-316, 2006. 